\title{
BMJ Open Epidemiological features of alcohol use in rural India: a population-based cross-sectional study
}

\author{
Sujit D Rathod, ${ }^{1}$ Abhijit Nadkarni, ${ }^{2}$ Arvin Bhana, ${ }^{3}$ Rahul Shidhaye ${ }^{4}$
}

To cite: Rathod SD,

Nadkarni A, Bhana A, et al. Epidemiological features of alcohol use in rural India: a population-based crosssectional study. BMJ Open 2015;5:e009802.

doi:10.1136/bmjopen-2015009802

- Prepublication history and additional material is available. To view please visit the journal (http://dx.doi.org/ 10.1136/bmjopen-2015009802).

Received 24 August 2015 Revised 24 September 2015 Accepted 5 October 2015

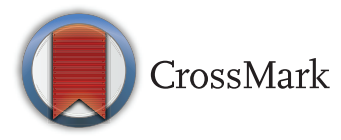

${ }^{1}$ Department of Population Health, London School of Hygiene and Tropical Medicine, London, UK

${ }^{2}$ Sangath, Goa, India

${ }^{3}$ School of Applied Human Sciences, University of KwaZulu-Natal, Durban, South Africa

${ }^{4}$ Centre for Mental Health, Public Health Foundation of India, New Delhi, India

Correspondence to Dr Sujit D Rathod; Sujit.rathod@Ishtm.ac.uk

\section{ABSTRACT}

Objectives: We sought to estimate the proportion of adults in Sehore District, India, who consumed alcohol, and the proportion who had behaviours consistent with alcohol use disorders (AUDs), using the Alcohol Use Disorders Identification Test (AUDIT). Among men who drank, we identified individual-level, household-level and community-level factors associated with AUDIT scores. Men with AUDs (AUDIT score $\geq 8$ ) reported on whether and where they had sought treatment, and about alcohol-related internal stigma.

Design: Population-based cross-sectional study. Setting: Rural villages and urban wards in Sehore District, Madhya Pradesh, India.

Participants: $n=3220$ adult ( $\geq 18$ years of age) residents of Sehore District.

Primary outcome measure: Score on the AUDIT.

Results: Nearly one in four men (23.8\%) had consumed alcohol in the past 12 months, while few $(0.6 \%)$ women were consumers. Among drinkers, $33.2 \%$ (95\% Cl $28.6 \%$ to $38.1 \%$ ) had AUDIT scores consistent with hazardous drinking, $3.3 \%(95 \% \mathrm{Cl}$ $2.1 \%$ to $5.1 \%)$ with harmful drinking and $5.5 \%(95 \%$ $\mathrm{Cl} 3.8 \%$ to $8.0 \%$ ) with dependent drinking. We observed that AUDIT scores varied widely by village (intraclass correlation $=0.052$ ). Among men who had recently consumed alcohol, AUDIT scores were positively associated with depression, having at least one child, high-quality housing, urban residence, tobacco use and disability. AUDIT scores were negatively associated with land ownership, out-ofpocket healthcare expenditure and participation in the national employment programme. While $49.2 \%$ of men with AUDs felt embarrassed by their problems with alcohol, only $2.8 \%$ had sought treatment in the past 12 months.

Conclusions: A need exists for effectively identifying and treating adults with AUDs. Health promotion services, informed by commonly-expressed stigmatised beliefs held among those affected by AUDs and which are targeted at the most affected communities, may be an effective step in closing the treatment gap.

\section{BACKGROUND}

Alcohol misuse is a major and increasingly attributable risk factor for morbidity and

\section{Strengths and limitations of this study}

- This is the first population-based survey of alcohol use to be conducted in Madhya Pradesh, India in 10 years, and one of the few studies of alcohol use in India to include women.

- We used a widely validated screening tool (AUDIT) to identify participants who had alcohol use disorders.

- Since this is a cross-sectional study, we are unable to determine whether any of the factors associated with AUDIT scores are causal relationships.

mortality worldwide. ${ }^{1-3}$ Studies of communities in India show that while the prevalence of alcohol abstention is relatively high, those who do drink are highly likely to engage in hazardous, harmful or dependent drinking behaviours, ${ }^{4-8}$ here collectively referred to as alcohol use disorders (AUDs) (International Classification of Diseases 10th Edition, ICD-10: Z72.1, F10.1, F10.2). ${ }^{9}$

While the impact of AUDs is direct (ie, through overdose or fetal alcohol syndrome), studies conducted in India demonstrate that much of the impact is mediated through increased risk of accidents, development or progression of chronic disease and acquisition of infection. ${ }^{10-14}$ Further, individuals affected by AUDs have broader social impacts through the increased risk of violence and the health and economic consequences of consumption or injury. ${ }^{5} 13$ 15-19 AUDs have consistently been identified as a public health concern over the past 20 years,${ }^{20-23}$ during which time per capita consumption of alcohol has increased by $55 \%,{ }^{24}$ and the treatment gap for those affected has remained persistently high. ${ }^{182526}$

The effects of AUDs have motivated the development of programmes such as Screening and Brief Intervention, which aim to reduce the frequency and intensity of alcohol consumption episodes. Screening and Brief Intervention has been shown to be 
effective and cost-effective in low-income settings, ${ }^{27}{ }^{28}$ where access to treatment services remains limited. ${ }^{29}$ The treatment gap in India has not been well characterised, nor have the characteristics of those individuals who need services. As a prerequisite to the adaptation and implementation of Screening and Brief Intervention, we conducted a study to describe the epidemiological features of alcohol consumption and of treatment-seeking among adults living in a rural district in India.

\section{METHODS}

\section{Setting}

Sehore District is a predominantly rural district in central India, with a population of 1.3 million people. At the time of this study, inpatient detoxification and rehabilitation services were available in Sehore city at a government-funded 15-bed facility. Additional detoxification and rehabilitation services were available in the public and private sectors in Bhopal city, approximately $34 \mathrm{~km}$ away from Sehore city. As part of the PRIME research programme consortium and in partnership with the Madhya Pradesh State Ministry of Health, Sehore District was selected to implement a district-level mental healthcare plan to integrate mental health diagnostic and treatment services into the primary healthcare sector. ${ }^{30}$ The primary aim of the PRIME Community Surveys is to detect a change in treatment-seeking among adults with alcohol use or depressive disorders. We conducted a baseline round of data collection immediately prior to implementation of the district-level mental health plan, and plan to conduct a follow-up round of data collection 18 months later.

\section{Sample and questionnaire}

In Sehore, a sample size of 3220 in each survey round provides over $80 \%$ power to detect a change in treatmentseeking among adults with AUDs from $5 \%$ to $20 \%$ with a two-sided $\alpha$ of 0.05 . We assumed that approximately $10 \%$ of adults would have AUDs. Since we planned to use a cluster sampling design, we used a conservative value of 0.10 for the intraclass correlation for treatment-seeking. We used 2011 census data ${ }^{31}$ to recruit this populationbased sample as follows: In proportion to the population distribution in the district, we selected 70 villages from the rural stratum and 19 wards from the urban stratum. Within each selected village/ward, we used simple random sampling to select one electoral polling station's voter list. ${ }^{32}$ Within the selected list, we randomly selected between 25 and 47 adults, with the variation in allocation being a function of the research assistants' time availability. The research assistant located the adult's household and contacted the adult, scheduled a return visit through another household member (if the selected adult was not present) or moved to the next adult of the same sex on the voting list (if the originally selected adult no longer resided at that address). On meeting the selected adult, the research assistant explained the aims of the study, assessed the adult for eligibility (ie, age $\geq 18$ years, fluent in Hindi and absence of intellectual impairment or acute medical issue) and scheduled eligible adults for an interview. The interviewers were male and female university graduates who were mostly residents of Sehore District. The interviewers orally administered a structured interview in Hindi, using a questionnaire application ${ }^{33}$ programmed on a tablet device.

The questionnaire consisted of sections pertaining to: sociodemographic characteristics; recent use of alcohol or tobacco; screening for alcohol use disorders; treatment-seeking and stigma for problems with alcohol; screening for depression; treatment-seeking and stigma for depression; suicidality; healthcare usage and out-of-pocket expenditures; and disability severity.

\section{Health-related measures}

The outcome measure of interest is the total score on the 10 -item AUDIT. $^{34}$ The AUDIT was developed by $\mathrm{WHO}$ and has been widely validated, including in India. ${ }^{35}{ }^{36}$ Respondents are asked about the frequency of different drinking behaviours and consequences over the past 12 months, and their responses are scored from 0 (Never occurs) to 4 (Daily). The sum of scores from the 10 items provides guidance on whether the respondent engages in hazardous (score 8-15), harmful (score 16-19) or dependent (score $\geq 20$ ) drinking behaviours, using cut-offs defined by WHO. ${ }^{34}$ Participants who had not consumed alcohol in the past 12 months were not administered the AUDIT and were allocated a score of 0 . Participants who had an AUDIT score of 8 or more were asked about their treatment-seeking, and then were asked 11 questions from the 29-item Internalized Stigma of Mental Illness scale ${ }^{37}$ with regard to 'problems with drinking'; these 11 items were selected for the questionnaire as they were relevant to the cultural and programmatic contexts across PRIME countries.

To measure depression severity, we administered the 9-item Patient's Health Questionnaire (PHQ-9) ${ }^{38}$ which has been validated in India ${ }^{39}{ }^{40}$-followed by a question on suicidal ideation which was adapted from the Mini International Neuropsychiatric Interview (MINI), a diagnostic tool for mental disorders. ${ }^{41}$ To measure disability, we administered the 12-item WHO Disability Assessment Schedule 2.0 (WHODAS), ${ }^{42}$ which has been widely validated for use in low income and middle income country settings. Using questions adapted from the Client Service Receipt Inventory, ${ }^{43}$ we asked participants whether they had any inpatient admissions to a hospital in the past 12 months, whether they had used any outpatient health services in the past 3 months, as well as out-of-pocket expenses for those outpatient services.

\section{Sociodemographic measures}

The items included in the sociodemographic section were adapted from the Indian version of the 
Demographic and Health Surveys. ${ }^{44}$ Participants were asked how many years of education they had completed, and from these responses we created categories for educational attainment ( 0 years, $1-5$ years, $6-11$ years, and $\geq 12$ years). As a proxy for socioeconomic status, we asked participants about whether they owned any land, as well as about the quality of their home construction; we used Government of India definitions to classify the homes into those with lower, average and higher quality. ${ }^{45}$ Participants were engaged in a wide range of occupations, and from these responses we adapted an occupation classification system ${ }^{46}$ to create four groups reflecting no occupation, non-income work (eg, household work, student), lower income work (eg, agriculture, unskilled manual) and higher income work (eg, teacher, police/military, skilled manual), as well as whether they had signed up to receive work assignments through a national employment programme.

\section{Statistical methods}

First, we described the sociodemographic characteristics and AUDIT scores of the full sample of 3220 adults and reported the distribution of the sample within each measurement stratum (eg, age group, education group). Then within each sociodemographic stratum, we reported the percentages of adults who had and had not consumed alcohol in the past 12 months. Among all participants and then among men, women and those who had recently consumed alcohol, we report the mean AUDIT score and the proportions who have AUDIT scores consistent with hazardous, harmful and dependent drinking. Next, using data from adults who had recently consumed alcohol, we estimated the

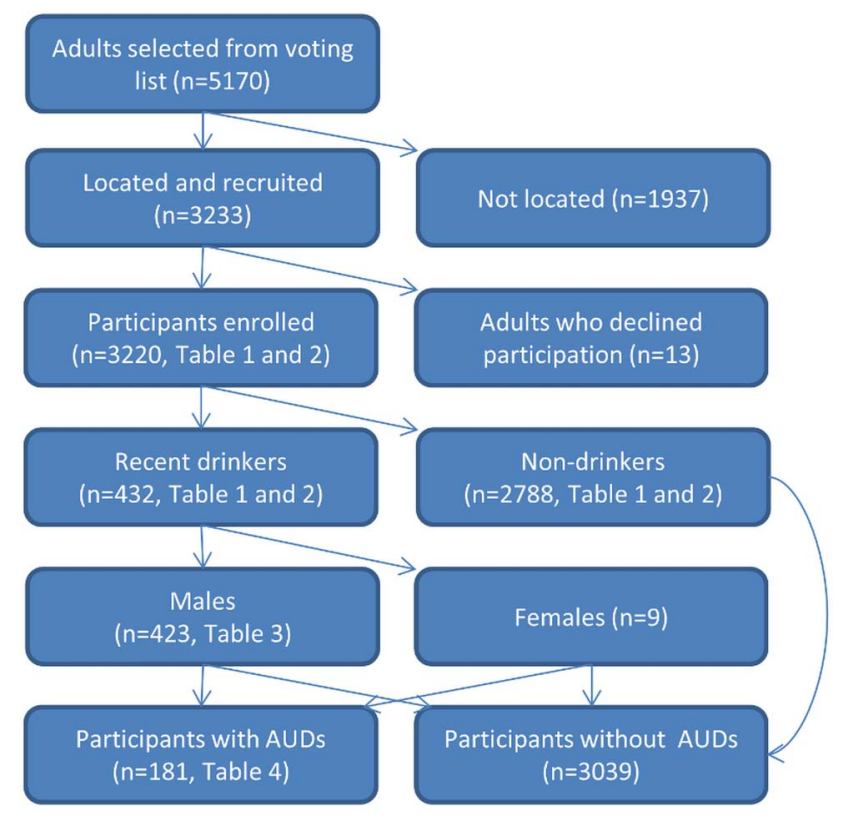

Figure 1 Participant flow diagram for PRIME Community Survey, Sehore District, India, 2013-2014. AUDs, alcohol use disorders internal consistency of the AUDIT score using Cronbach's $\alpha$, and using data from all adults we estimated the intraclass correlation for clustering of AUDIT scores by ward/village using large one-way analysis of variance.

Previous research conducted in India has demonstrated that alcohol consumption is almost universally a male activity. Thus, we restricted the next analysis of the sample to male participants who reported consuming alcohol in the past 12 months. With these participants, we used univariable zero-truncated negative binomial regression models to assess individual-level, household-level and community-level characteristics, inpatient care, outpatient out-of-pocket expenditure, tobacco use and depression and disability severity for their association with the AUDIT score. The negative binomial regression model is suitable for skewed outcome data, and produces coefficients which-once exponentiated-are interpreted as the relative difference in the AUDIT score for every unit change in the independent variable. We have analysed the AUDIT score as a continuous score rather than a binary category as we are interested in risk factors associated with increasing harm from alcohol, which can inform development of population-level strategies to reduce those risks. In contrast, analysis of a binary category would be more suitable to inform clinical care, where only high-scoring individuals would receive referral for treatment. For each regression model, we report the exponentiated $\beta$ coefficients and their 95\% CIs. We combined strata when one stratum comprised less than $0.1 \%$ of the population of male drinkers (eg, 'No caste' combined with 'general caste').

Finally, we further restricted the sample to participants who had AUDIT scores of 8 or more. We describe the treatment-seeking behaviour, if any, of these participants and tabulated the frequency of affirmative response to questions about internalised stigma beliefs (figure 1).

We completed all analyses in Stata/IC 13.1 (College Station, USA), and adjusted all mean, percentage and regression coefficient figures for the complex sampling design. (see online supplementary material).

\section{Ethics}

Interviewers gave eligible adults oral and written information about the study and consenting adults provided a signature (or thumb print for low-literacy adults). For adults who expressed suicidal ideation during the interview process, the interviewer provided a referral to a research psychiatrist.

\section{RESULTS}

We conducted the survey in two waves (May-June 2013 and January-March 2014), during which time we selected 5170 adults from voting lists for recruitment, of whom we were able to contact 3233 . Of the 3233 adults we were able to contact, 3220 provided informed 
consent (survey response rate $=99.6 \%$ ). Consistent with the overall population distribution of Sehore District, most of the 3220 participants (78\%) were recruited from the rural stratum and the remainder $(22 \%)$ from the urban stratum. The sociodemographic characteristics of the sample are described in table 1 . The mean age of the adults was 40.2 years (SD 15.1) and 55\% were male. Most adults were Hindu (90\%), currently married $(85 \%)$ and had at least one child $(94 \%)$. Educational attainment was low, as $28 \%$ of adults never attended school and another 23\% started but did not complete primary school (23\%). Few participants $(9 \%)$ had a higher income occupation.

Across the entire population, $13.3 \%$ of adults $(95 \%$ CI $11.6 \%$ to $15.2 \%$ ) had consumed alcohol at least once in the past year; the sociodemographic stratum-specific prevalences of alcohol consumption are presented in table 1. Alcohol consumption varied widely between sociodemographic groups: while $23.8 \%$ of men and $14.7 \%$ of Hindus had consumed alcohol in the past 12 months, only $0.6 \%$ of women and $1.2 \%$ of Muslims did. Among those who had recently consumed alcohol, the internal consistency of the AUDIT screening tool was high (Cronbach's $\alpha=0.783$ ). The intraclass correlation for AUDIT scores was 0.052: though the mean AUDIT score for males across Sehore District was 1.0, the cluster-specific means (for individual villages or wards) ranged from 0.00 to 5.3 (figure 2). The alcohol consumption patterns for women, men and currently drinkers are presented in table 2. Recent consumption of alcohol was acknowledged by a minority of women $(0.6 \%)$ and men $(23.8 \%)$, and the mean AUDIT scores for these groups were 0.03 and 1.8, respectively. Among those who had recently consumed alcohol, the mean AUDIT score was $7.5 ; 33.2 \%$ of these individuals had an AUDIT score which was consistent with hazardous alcohol consumption behaviour (AUDIT score 8-15), $3.3 \%$ with harmful behaviour (AUDIT score 16-19) and $5.5 \%$ with dependent behaviour (AUDIT score $\geq 20$ ).

The correlates of AUDIT scores among male drinkers are described in table 3. AUDIT scores were $65 \%$ lower for drinkers who were widowed, divorced, separated or deserted (relative score $=0.35,95 \%$ CI 0.17 to 0.72 ) relative to those who were married. For each unit increase in PHQ9 score, the AUDIT score was 5\% higher (relative score $=1.05,95 \%$ CI 1.03 to 1.07 ). Having at least one child, high-quality housing, urban residence, suicidal ideation, tobacco use and disability were all positively associated with AUDIT scores, whereas land ownership, out-of-pocket healthcare expenditure and participation in the national employment programme were negatively associated with AUDIT scores. We did not find evidence of differences in AUDIT scores by religion, caste, occupation type or use of inpatient care.

Of the adults with AUD, only $2.8 \%$ had sought treatment for problems with drinking in the past 12 months, primarily from traditional healers. Nearly one in four (23.9\%) adults with AUDs spoke to another person

\begin{tabular}{|c|c|c|c|}
\hline \multirow[t]{2}{*}{ Characteristic } & \multirow[b]{2}{*}{$\begin{array}{l}\text { Proportion of } \\
\text { total (\%) }\end{array}$} & \multicolumn{2}{|c|}{$\begin{array}{l}\text { Current } \\
\text { drinker }\end{array}$} \\
\hline & & $\begin{array}{l}\text { Per } \\
\text { cent } \\
\text { No }\end{array}$ & $\begin{array}{l}\text { Per } \\
\text { cent } \\
\text { Yes }\end{array}$ \\
\hline \multicolumn{4}{|l|}{ Age (years) } \\
\hline $18-29$ & 27.6 & 84.2 & 15.8 \\
\hline $30-49$ & 47.0 & 87.2 & 12.8 \\
\hline$\geq 50$ & 25.4 & 88.4 & 11.6 \\
\hline \multicolumn{4}{|l|}{ Sex } \\
\hline Female & 45.4 & 99.4 & 0.6 \\
\hline Male & 54.6 & 76.2 & 23.8 \\
\hline \multicolumn{4}{|l|}{ Religion } \\
\hline Hindu & 89.8 & 85.3 & 14.7 \\
\hline Muslim & 10.2 & 98.8 & 1.2 \\
\hline Other & $<0.1$ & & \\
\hline \multicolumn{4}{|l|}{ Caste } \\
\hline General & 13.1 & 91.4 & 8.6 \\
\hline Scheduled caste & 19.7 & 77.0 & 23.0 \\
\hline Scheduled tribe & 5.1 & 69.6 & 30.4 \\
\hline Other backward caste & 62.1 & 90.2 & 9.8 \\
\hline None & $<0.1$ & & \\
\hline \multicolumn{4}{|l|}{ Marital status } \\
\hline Currently married & 84.6 & 86.3 & 13.7 \\
\hline Unmarried & 10.5 & 85.7 & 14.3 \\
\hline Widow(er) & 4.4 & 97.6 & 2.4 \\
\hline $\begin{array}{l}\text { Divorced, separated, } \\
\text { deserted }\end{array}$ & 0.5 & 84.0 & 16.0 \\
\hline \multicolumn{4}{|l|}{ Children* } \\
\hline 0 & 5.9 & 80.8 & 19.2 \\
\hline$\geq 1$ & 94.1 & 87.2 & 12.8 \\
\hline \multicolumn{4}{|c|}{ Educational attainment (years) } \\
\hline 0 & 28.1 & 92.2 & 7.8 \\
\hline $1-5$ & 22.8 & 86.3 & 13.7 \\
\hline $6-11$ & 36.5 & 83.0 & 17.0 \\
\hline$\geq 12$ & 12.6 & 85.8 & 14.2 \\
\hline \multicolumn{4}{|l|}{ Housing quality } \\
\hline Lower & 43.6 & 84.3 & 15.7 \\
\hline Average & 26.2 & 89.2 & 10.8 \\
\hline Higher & 30.1 & 87.9 & 12.1 \\
\hline \multicolumn{4}{|l|}{ Owns land } \\
\hline No & 73.0 & 87.5 & 12.5 \\
\hline Yes & 27.0 & 84.5 & 15.5 \\
\hline \multicolumn{4}{|l|}{ Occupation type } \\
\hline None & 4.1 & 81.7 & 18.3 \\
\hline Non-income & 33.6 & 98.4 & 1.6 \\
\hline Lower income & 53.0 & 81.1 & 18.9 \\
\hline Higher income & 9.3 & 78.4 & 21.6 \\
\hline \multicolumn{4}{|c|}{ Working in employment programme } \\
\hline No & 92.5 & 87.2 & 12.8 \\
\hline Yes & 7.5 & 80.6 & 19.4 \\
\hline
\end{tabular}

Percentage figures are adjusted for the complex sampling design. *Among ever married respondents.

about their drinking, primarily to a spouse/partner or a friend.

The internalised stigma beliefs of adults with AUDs are presented in table 4 . Nearly half of these adults felt 


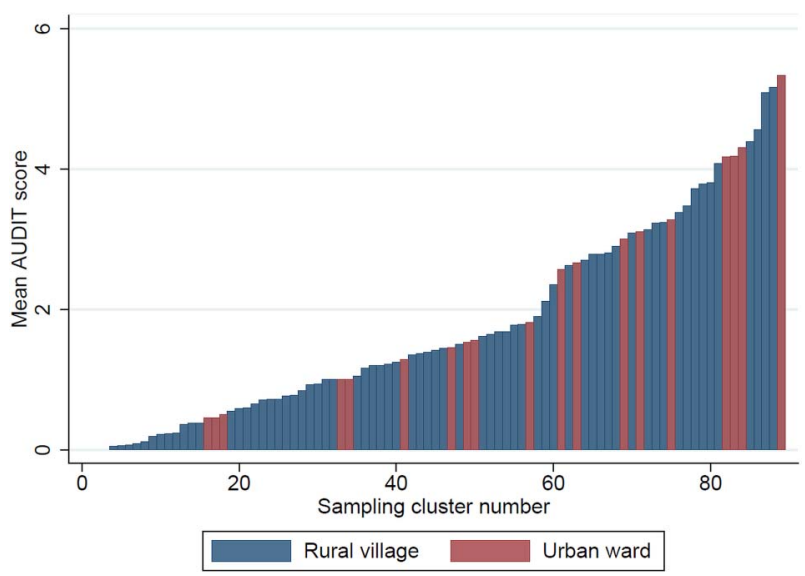

Figure 2 Distribution of mean AUDIT score for male residents of selected villages and wards in Sehore District, India, 2013-2014. AUDIT, Alcohol Use Disorders Identification Test.

embarrassment or shame $(49.2 \%)$ or disappointment in themselves $(47.2 \%)$ because of problems with drinking. A few of these adults reported that they were unable to make their own decisions $(20.3 \%)$ or that they were ignored $(16.6 \%)$ because of their problems with alcohol.

\section{DISCUSSION}

In Sehore District, we found that a minority (13.3\%) of adults consumed alcohol in the past 1 year, though a substantial proportion $(42 \%)$ of the adults who did consume alcohol had behaviours consistent with alcohol use disorders. AUDIT scores were positively associated educational attainment, urban residence, having children, high-quality housing, depression severity, disability severity and usage of tobacco products. Adults who had AUDs were unlikely to have sought treatment from a medical provider, were likely to feel personal shame, but were not likely to feel social stigma.

The PRIME Community Survey is notable for being a large, population-based survey of alcohol use in Sehore District, and this is the first such study to be conducted in Madhya Pradesh State in 10 years. That prior study only considered whether respondents consumed alcohol or not and combined data across multiple states in
India. These data advance understanding by measuring the intensity of alcohol use, and in a single, defined population. We measured alcohol use with the AUDIT tool, which had been validated elsewhere in India, ${ }^{35} 36$ and demonstrated here a high value for internal consistency.

The drinking population in Sehore District comprised a small proportion of men from the general population, within which a large proportion engages in hazardous, harmful or dependent drinking behaviours (table 2). These findings are consistent with the two other alcohol surveys conducted in Madhya Pradesh state ${ }^{47} 48$ as well as elsewhere in India ${ }^{725} 49$ ). Multiround cross-sectional studies such as the PRIME Community Surveys are required to evaluate whether the prevalence of drinkers is increasing, particularly among women and whether those who do drink are increasing their consumption intensity. An understanding of these trends will help guide the health promotion messaging for the targeted population, and further support expansion of programmes for screening and brief intervention, and more intensive programmatic interventions.

In this study, the clustering coefficient for the AUDIT score provides evidence of a geographic component to drinking behaviours, such that a portion of an individual's AUDIT score is explained by the scores of other drinkers within the same village/ward. Evidence of geographic clustering was also present in the findings from a study of health facility attendees in Goa, India. ${ }^{5}$ Further, a multistate survey of alcohol use in India, which included Madhya Pradesh state, found that 11\% of the variance in drinking was explained by that individual's area of residence. ${ }^{47}$ Additionally, an explanatory models study in Goa identified a person's peers as a key influence on alcohol use disorders. ${ }^{50}$ The policy implication of these findings is that a community-level focus for health promotion programmes (eg, working with local non-governmental organisations and village health workers) may be necessary and conducted in addition to population-level programmes (eg, through legislation or taxation) in changing alcohol consumption patterns.

Recent consumption of alcohol was far higher among Hindus $(14.7 \%)$ than Muslims (1.2\%), a finding which is consistent with national patterns. ${ }^{47}$ In contrast to a generally understood prohibition on alcohol

Table 2 Alcohol consumption among adults in Sehore District, India, 2013-2014

\begin{tabular}{|c|c|c|c|c|}
\hline & All adults (95\% Cl) & Women $(95 \% \mathrm{Cl})$ & Men $(95 \% \mathrm{Cl})$ & Recent drinkers (95\% Cl) \\
\hline AUDIT score, mean & $1.0(0.8$ to 1.2$)$ & $0.03(0.0$ to 0.1$)$ & 1.8 (1.5 to 2.1$)$ & 7.5 (6.9 to 8.0$)$ \\
\hline Recent drinker, \% & 13.3 (11.6 to 15.2$)$ & $0.6(0.3$ to 1.1$)$ & 23.8 (20.8 to 27.1$)$ & 100.0 \\
\hline Hazardous drinking, \% & 4.4 (3.6 to 5.4$)$ & $0.1(0.0$ to 0.5$)$ & $8.0(6.5$ to 9.8$)$ & 33.2 (28.6 to 38.1$)$ \\
\hline Harmful drinking, \% & $0.4(0.3$ to 0.7$)$ & 0.0 & 0.7 (0.4 to 1.3$)$ & $3.3(2.1$ to 5.1$)$ \\
\hline Dependent drinking, \% & $0.7(0.5$ to 1.1$)$ & 0.0 & 1.3 (0.8 to 2.0$)$ & 5.5 (3.8 to 8.0$)$ \\
\hline
\end{tabular}


Table 3 Sociodemographic and health-related correlates of AUDIT scores among adult males who recently drank alcohol in Sehore District, India, 2013-2014

\begin{tabular}{|c|c|c|}
\hline & $\begin{array}{l}\text { Relative } \\
\text { score }\end{array}$ & $95 \% \mathrm{Cl}$ \\
\hline Age (per 10 years) & $0.94^{*}$ & 0.87 to 1.01 \\
\hline \multicolumn{3}{|l|}{ Caste } \\
\hline General/none & Ref. & \\
\hline Other backward caste & 0.99 & 0.72 to 1.35 \\
\hline Scheduled tribe/caste & 0.89 & 0.66 to 1.21 \\
\hline \multicolumn{3}{|l|}{ Religion } \\
\hline Muslim/other & Ref. & \\
\hline Hindu & 0.69 & 0.35 to 1.36 \\
\hline \multicolumn{3}{|l|}{ Education (years) } \\
\hline 0 & Ref. & \\
\hline $1-5$ & $1.43^{*}$ & 0.98 to 2.09 \\
\hline $6-11$ & $1.40^{*}$ & 0.97 to 2.01 \\
\hline$\geq 12$ & 1.15 & 0.78 to 1.69 \\
\hline \multicolumn{3}{|l|}{ Marital status } \\
\hline Currently married & Ref. & \\
\hline Unmarried & 0.93 & 0.71 to 1.21 \\
\hline $\begin{array}{l}\text { Widowed/ divorced/separated/ } \\
\text { deserted }\end{array}$ & $0.35^{\star *}$ & 0.17 to 0.72 \\
\hline \multicolumn{3}{|l|}{ Childrent } \\
\hline \multicolumn{3}{|l|}{0} \\
\hline$\geq 1$ & $1.32^{*}$ & 0.97 to 1.80 \\
\hline \multicolumn{3}{|l|}{ Occupation type } \\
\hline None & 1.06 & 0.54 to 2.07 \\
\hline Non-income & Ref. & \\
\hline Lower income & 1.31 & 0.80 to 2.16 \\
\hline Higher income & 1.07 & 0.61 to 1.87 \\
\hline \multicolumn{3}{|c|}{ Working in employment programme } \\
\hline No & Ref. & \\
\hline Yes & $0.66^{\star \star}$ & 0.48 to 0.90 \\
\hline \multicolumn{3}{|l|}{ Owns land } \\
\hline No & Ref. & \\
\hline Yes & $0.82^{\star \star}$ & 0.68 to 0.98 \\
\hline \multicolumn{3}{|l|}{ Housing quality } \\
\hline Lower & Ref. & \\
\hline Average & 1.11 & 0.88 to 1.40 \\
\hline Higher & $1.26^{\star \star}$ & 1.03 to 1.54 \\
\hline \multicolumn{3}{|l|}{ Residential stratum } \\
\hline Rural & Ref. & \\
\hline Urban & $1.19^{\star \star}$ & 1.01 to 1.39 \\
\hline \multicolumn{3}{|l|}{ Currently uses tobacco products } \\
\hline No & Ref. & \\
\hline Yes & $1.50^{\star \star}$ & 1.09 to 2.07 \\
\hline Depression severity (PHQ9 score) & $1.05^{\star \star}$ & 1.03 to 1.07 \\
\hline \multicolumn{3}{|l|}{ Suicidal ideation } \\
\hline No & Ref. & \\
\hline Yes & $1.29^{*}$ & 0.96 to 1.74 \\
\hline \multicolumn{3}{|l|}{ Inpatient care } \\
\hline No & Ref. & \\
\hline Yes & 1.04 & 0.76 to 1.41 \\
\hline $\begin{array}{l}\text { Outpatient care expenditure (per } \\
\text { US } \$ 100 \ddagger \text { ) }\end{array}$ & $0.72^{\star *}$ & 0.53 to 0.99 \\
\hline $\begin{array}{l}\text { Disability severity (WHODAS } \\
\text { score) }\end{array}$ & $1.03^{\star *}$ & 1.01 to 1.05 \\
\hline
\end{tabular}

Relative score and $95 \%$ Cls are estimated with zero truncated negative binomial regression, and are adjusted for the complex sampling design.

${ }^{*} 0.05<\mathrm{p}<0.10$.

${ }^{* *} p<0.05$.

†Among ever married respondents.

fUS\$1=62.162 Indian rupees on 3 March 2014.

AUDIT, Alcohol Use Disorders Identification Test ; PHQ9, Patient Health Questionnaire 9; Ref., Reference category; WHODAS,

WHO Disability Assessment Schedule. consumption for all adherents of Islam, the historical record for Hindus contains a multitude of references to alcohol use, even for ceremonial usage. ${ }^{51}$ It should be noted, though, that while religious affiliation is predictive of whether an adult drinks alcohol or not, religious affiliation was not associated with the intensity of consumption among male drinkers.

AUDIT scores were positively associated with tobacco use, depression and disability, which is broadly consistent with other data reported from India. ${ }^{5} 61314182652$ However, like Silva's study of male industrial workers in Goa,${ }^{26}$ we did not find a positive association of AUDIT scores with receipt of inpatient care.. Male drinkers with higher AUDIT scores had lower out-of-pocket expenditure for outpatient care, in contrast to the increased healthcare usage which has been observed for people with AUDs elsewhere in India. ${ }^{16}{ }^{18}{ }^{26}$ Further research is needed to clarify this relationship. It is possible that in Sehore, chronically unwell people curtail their drinking and that heavy drinkers avoid engagement with the health sector. Taken as a whole, our findings indicate that there are multiple domains of poor health concurrently present in adults with higher AUDIT scores. We found that only a small minority of people with alcohol use disorder sought treatment, or communicated their problems with alcohol. Treatment-seeking by those with problems with alcohol in India is an infrequent occurrence, ${ }^{182526}$ and is partially due to lack of public treatment services and inaccessibility of private services. ${ }^{21}$ Yet recognition that problems with alcohol are medical in nature is rare, ${ }^{25} 50$ and most likely contributes to both the low supply of and demand for treatment services. Given the need for, and the low level of uptake of, services, it may be useful to consider the role of community health workers in implementing screening and brief intervention programmes.

Feelings of personal shame are commonly expressed by people with AUDs in India ${ }^{1825} 50$ and elsewhere. The stigmatising beliefs endorsed by adults here most likely impede treatment-seeking, and must be directly addressed as part of any increase in the supply of treatment services. A future study of explanatory models, such as has been conducted in Goa, India, ${ }^{50}$ is an appropriate means to identify the full range of stigmatising beliefs and the means to overcome them.

There are some important limitations to consider. Since we have used a self-report questionnaire, social desirability and the individual's unwillingness to acknowledge that they drink or have specific problems with alcohol are likely to have biased our prevalence estimates downward and thereby reduced the magnitude of effect estimates in the regression models. Second, since we used a cross-sectional study design, we are unable to make causal inferences, or to establish the direction of associations. For example, we observed a positive association between AUDIT scores and symptoms of depression: while a known consequence of alcohol consumption is the manifestation of depressive 
Table 4 Internal stigma beliefs among adults with alcohol use disorders in Sehore District, 2013-2014

\begin{tabular}{|c|c|c|}
\hline \multirow[b]{2}{*}{ Belief } & \multicolumn{2}{|c|}{ 'Agree' or 'Strongly agree’ } \\
\hline & Per cent & $95 \% \mathrm{Cl}$ \\
\hline I am embarrassed by or ashamed of these problems & 49.2 & 42.3 to 56.0 \\
\hline I am disappointed in myself due to these problems & 47.2 & 39.6 to 54.8 \\
\hline Others think that I cannot achieve much in life because of these problems & 39.7 & 32.9 to 46.4 \\
\hline I feel out of place in the world because of these problems & 38.5 & 32.0 to 45.0 \\
\hline These problems have spoilt my life & 38.4 & 30.9 to 45.9 \\
\hline People take me less seriously because of these problems & 30.2 & 23.1 to 37.3 \\
\hline People discriminate against me due to these problems & 28.7 & 22.2 to 35.1 \\
\hline Nobody would be interested in getting close to me because of these problems & 27.8 & 21.0 to 34.6 \\
\hline I cannot contribute anything to society because of these problems & 21.6 & 15.5 to 27.6 \\
\hline Owing to these problems, I need others to make most decisions for me & 20.3 & 14.9 to 25.6 \\
\hline People ignore me just because of these problems & 16.6 & 11.1 to 22.1 \\
\hline
\end{tabular}

symptoms, ${ }^{53}$ it is also common for people with psychiatric conditions to self-medicate with alcohol. ${ }^{54}$ Finally, the effect estimates in the regression models may be biased by confounding factors. Further research must investigate the hypotheses generated in this analysis, which can adjust for potential confounders accordingly. Similarly, the prevalence and regression estimates presented here are population-level estimates and there may be important stratum-specific estimates (eg, by sex, religion or caste) which will require consideration of effect modification to assess.

In conclusion, it is evident that a need exists for effectively identifying and treating adults with AUDs. The existing capacity for service provision is inadequate to meet current need, and the treatment gap will continue to increase given that the prevalence and intensity of alcohol consumption is rising in India. ${ }^{24} 55$ Health promotion services, informed by commonly expressed stigmatised beliefs held among those affected by AUDs and which are targeted at the most affected communities, may be an effective step in closing the treatment gap.

Acknowledgements The authors thank Vaibhav Murhar and Dr Sanjay Shrivastava of Sangath, India, Dr Sandesh Samudre, Narendra Verma and Bhagwant Chilhate of the Public Health Foundation of India, and Dr Rajeev Mohan. Also, The authors extend our appreciation to the officials of the Department of Public Health and Family Welfare, Government of Madhya Pradesh, India.

Contributors SDR and RS conceived and designed the study. SDR analysed the data and drafted the manuscript. AB, AN and RS revised the manuscript, providing intellectual content. All authors commented on and approved the final manuscript.

Funding This study is an output of the PRogramme for Improving Mental health carE (PRIME) which was funded by UK aid from the UK Government (GB-1-201446); however, the views expressed do not necessarily reflect the UK Government's official policies. The funders had no role in study design, data collection and analysis, decision to publish or preparation of the manuscript.

Competing interests None declared.

Ethics approval Sangath (Goa, India), University of Cape Town (South Africa) and WHO (Geneva, Switzerland).

Provenance and peer review Not commissioned; externally peer reviewed.
Data sharing statement Interested parties may notify the PRIME investigators of their interest in collaboration, including access to the data set analysed here, through the following website: https://docs.google.com/forms/d/14oNm5xdEPIq-RjL_4GUyCPMpVWtyaNVcfDewnx-iL4/viewform

Open Access This is an Open Access article distributed in accordance with the Creative Commons Attribution Non Commercial (CC BY-NC 4.0) license, which permits others to distribute, remix, adapt, build upon this work noncommercially, and license their derivative works on different terms, provided the original work is properly cited and the use is non-commercial. See: http:// creativecommons.org/licenses/by-nc/4.0/

\section{REFERENCES}

1. Whiteford HA, Degenhardt L, Rehm J, et al. Global burden of disease attributable to mental and substance use disorders: findings from the Global Burden of Disease Study 2010. Lancet 2013;382:1575-86.

2. Lim SS, Vos T, Flaxman AD, et al. A comparative risk assessment of burden of disease and injury attributable to 67 risk factors and risk factor clusters in 21 regions, 1990-2010: a systematic analysis for the Global Burden of Disease Study 2010. Lancet 2012;380:2224-60.

3. Rehm J, Mathers C, Popova S, et al. Global burden of disease and injury and economic cost attributable to alcohol use and alcohol-use disorders. Lancet 2009;373:2223-33.

4. Gupta PC. Alcohol consumption among middle-aged and elderly men: a community study from western India. Alcohol Alcohol 2003;38:327-31.

5. D'Costa G, Nazareth I, Naik D, et al. Harmful alcohol use in Goa, India, and its associations with violence: a study in primary care. Alcohol Alcohol 2006;42:131-7.

6. Kim S, Rifkin S, John SM, et al. Nature, prevalence and risk factors of alcohol use in an urban slum of Southern India. Natl Med $J$ India 2013;26:203-9.

7. Jonas JB, Nangia V, Rietschel M, et al. Prevalence of depression, suicidal ideation, alcohol intake and nicotine consumption in rural Central India. The Central India Eye and Medical Study. PLOS ONE 2014;9:e113550.

8. Saxena S. Country profile on alcohol in India. In: Riley L, Marshall $\mathrm{M}$, eds. Alcohol and public health in 8 developing countries. Geneva, Switzerland: World Health Organization, 1999:37-60. http:// whqlibdoc.who.int/hq/1999/WHO_HSC_SAB_99.9.pdf?ua=1

9. World Health Organization. The $\overline{I C D}-10$ classification of mental and behavioural disorders: clinical descriptions and diagnostic guidelines. Geneva: World Health Organization, 1992.

10. Gajalakshmi V, Peto R. Smoking, drinking and incident tuberculosis in rural India: population-based case-control study. Int J Epidemiol 2009;38:1018-25.

11. Znaor A, Brennan P, Gajalakshmi V, et al. Independent and combined effects of tobacco smoking, chewing and alcohol drinking on the risk of oral, pharyngeal and esophageal cancers in Indian men. Int J Cancer J Int Cancer 2003;105:681-6.

12. Go VF, Solomon S, Srikrishnan AK, et al. HIV rates and risk behaviors are low in the general population of men in Southern India 
but high in alcohol venues: results from 2 probability surveys. J Acquir Immune Defic Syndr 2007;46:491-7.

13. Kunar BM, Bhattacherjee A, Chau N. Relationships of job hazards, lack of knowledge, alcohol use, health status and risk taking behavior to work injury of coal miners: a case-control study in India. J Occup Health 2008;50:236-44.

14. Pednekar MS, Sansone G, Gupta PC. Association of alcohol, alcohol and tobacco with mortality: findings from a prospective cohort study in Mumbai (Bombay), India. Alcohol 2012;46:139-46.

15. Nayak MB, Patel V, Bond JC, et al. Partner alcohol use, violence and women's mental health: population-based survey in India. $\mathrm{Br} J$ Psychiatry 2010;196:192-9.

16. Bonu S, Rani M, Peters DH, et al. Does use of tobacco or alcohol contribute to impoverishment from hospitalization costs in India? Health Policy Plan 2005;20:41-9.

17. Mayston R, Patel V, Abas M, et al. Determinants of common mental disorder, alcohol use disorder and cognitive morbidity among people coming for HIV testing in Goa, India. Trop Med Int Health 2015;20:397-406

18. Gaunekar G, Patel V, Rane A. The impact and patterns of hazardous drinking amongst male industrial workers in Goa, India. Soc Psychiatry Psychiatr Epidemiol 2005;40:267-75.

19. Saxena S, Sharma R, Maulik PK. Impact of alcohol use on poor families: a study from North India. J Subst Use 2003;8:78-84.

20. Prasad R. Alcohol use on the rise in India. Lancet 2009;373:17-18.

21. Saxena S. Alcohol problems and responses: challenges for India. $J$ Subst Use 2000;5:62-70.

22. Benegal V. India: alcohol and public health. Addiction 2005;100:1051-6.

23. Patel V. Personal views: the politics of alcoholism in India. BMJ 1998;316:1394.

24. Sassi F, Devaux M. Alcohol consumption and harmful drinking. 2015 May. Report No.: 79. http://www.oecd-ilibrary.org/social-issuesmigration-health/alcohol-consumption-and-harmful-drinking 5js1qwkz2p9s-en

25. Pal HR, Yadav S, Joy PS, et al. Treatment nonseeking in alcohol users: a community-based study from North India. J Stud Alcohol 2003;64:631-3.

26. Silva MC, Gaunekar G, Patel V, et al. The prevalence and correlates of hazardous drinking in industrial workers: a study from Goa, India. Alcohol Alcohol 2003;38:79-83.

27. Benegal V, Chand PK, Obot IS. Packages of care for alcohol use disorders in low- and middle-income countries. PLoS Med 2009;6: e1000170.

28. Anderson P, Chisholm D, Fuhr DC. Effectiveness and cost-effectiveness of policies and programmes to reduce the harm caused by alcohol. Lancet 2009;373:2234-46.

29. Perngparn U, Assanangkornchai S, Pilley C, et al. Drug and alcohol services in middle-income countries. Curr Opin Psychiatry 2008;21:229-33.

30. Lund C, Tomlinson M, De Silva M, et al. PRIME: A programme to reduce the treatment gap for mental disorders in five low- and middle-income countries. PLOS Med 2012;9:e1001359.

31. Sinha S. District Census Handbook: Sehore. Bhopal, Madhya Pradesh, India: Directorate of Census Operations, 2014 Mar. Report No.: Series-24, Part XII-B. http://www.censusindia.gov.in/ 2011census/dchb/2328 PART B DCHB SEHORE pd

32. Office of the Chief Electoral Officer. CEO MP: Voter list. In: CEO MP: Voter List [Internet]. (cited 24 Jun 2015). http://www. ceomadhyapradesh.nic.in/voterlist2015.aspx

33. Mobenzi Researcher [Internet]. Cape Town, South Africa: Clyral; http://mobenzi.com/researcher/home

34. Babor TF, Higgins-Biddle JC, Saunders JB, et al. AUDIT: the alcohol use disorders identification test guidelines for use in primary care. Geneva, Switzerland: World Health Organization, 2001.

35. Pal HR, Jena R, Yadav D. Validation of the Alcohol Use Disorders Identification Test (AUDIT) in urban community outreach and de-addiction center samples in north India. J Stud Alcohol 2004;65:794-800.

36. Nayak MB, Bond JC, Cherpitel C, et al. Detecting alcohol-related problems in developing countries: a comparison of 2 screening measures in India. Alcohol Clin Exp Res 2009;33:2057-66.

37. Boyd Ritsher J, Otilingam PG, Grajales M. Internalized stigma of mental illness: psychometric properties of a new measure. Psychiatry Res 2003;121:31-49.

38. Kroenke K, Spitzer RL, Williams JB. The PHQ-9. J Gen Intern Med 2001;16:606-13.

39. Patel V, Araya R, Chowdhary N, et al. Detecting common mental disorders in primary care in India: a comparison of five screening questionnaires. Psychol Med 2008;38:221-8.

40. Ganguly S, Samanta M, Roy P, et al. Patient health questionnaire-9 as an effective tool for screening of depression among Indian adolescents. J Adolesc Health 2013;52:546-51.

41. Sheehan D, Janavs J, Baker R, et al. MINI-Mini International Neuropsychiatric Interview-English Version 5.0. 0-DSM-IV. J Clin Psychiatry 1998;59:34-57.

42. Üstün TB, Kostanjsek N, Chatterji S, Rehm J, eds. Measuring health and disability: manual for WHO Disability Assessment Schedule WHODAS 2.0. Geneva: World Health Organization, 2010

43. Beecham J, Knapp M. Costing psychiatric interventions. In: Thornicroft G, ed. Measuring mental health needs. 2nd edn. London: Gaskell/Royal College of Psychiatrists, 2001:200-24.

44. International Institute for Population Sciences, Macro International. India National Family Health Survey (NFHS-3), 2005-06. Mumbai, India: International Institute for Population Sciences, 2007.

45. Anant TCA, Das SK. Housing [Internet]. New Delhi, India: Ministry of Statistics and Progamme Implementation, 2011:352. Report No.: 44th edition. http://mospi.nic.in/Mospi_New/upload/ statistical_year_book_2011/SECTOR-4-SERVICE SECTOR/ CH-28-HOUSING/HOUSING-WRITEUP.pdf

46. Lund $\mathrm{C}$, Waruguru $\mathrm{M}$, Kingori J, et al. Outcomes of the mental health and development model in rural Kenya: a 2-year prospective cohort intervention study. Int Health 2013;5:43-50.

47. Subramanian SV, Nandy S, Kelly M, et al. Health behaviour in context: exploratory multi-level analysis of smoking, drinking and tobacco chewing in four states. Econ Polit Wkly 2004; 39:684-93.

48. Mohan D, Chopra A, Ray R, et al. Alcohol consumption in India: a cross sectional study. In: Demers A, Room R, Bourgault C, eds. Surveys of drinking patterns and problems in seven developing countries. Geneva, Switzerland: World Health Organization, 2001:103-14.

49. Ganesh KS, Premarajan KC, Subitha L, et al. Prevalence and pattern of alcohol consumption using Alcohol Use Disorders Identification Test (AUDIT) in rural Tamil Nadu, India. J Clin Diagn Res 2013;7:1637-9.

50. Nadkarni A, Dabholkar H, McCambridge J, et al. The explanatory models and coping strategies for alcohol use disorders: an exploratory qualitative study from India. Asian J Psychiatry 2013:6:521-7.

51. Murthy P. Culture and alcohol use in India. World Cult Psychiatry Res Rev 2015:10:27-39.

52. Pillai A, Nayak MB, Greenfield TK, et al. Patterns of alcohol use, their correlates, and impact in male drinkers: a population-based survey from Goa, India. Soc Psychiatry Psychiatr Epidemio 2013;48:275-82.

53. Schuckit MA. Comorbidity between substance use disorders and psychiatric conditions. Addict Abingdon Engl 2006;101(Suppl 1):76-88.

54. Harris KM, Edlund MJ. Self-medication of mental health problems: new evidence from a national survey. Health Serv Res 2005;40:117-34.

55. Global status report on alcohol and health, 2014. Geneva, Switzerland: World Health Organization, 2014. http://alltitles.ebrary com/Doc?id=10931311 